\title{
The Prognostic Value of Descending Aorta to Main Pulmonary Artery Enhancement Ratio in Massive or Sub-Massive Acute Pulmonary Embolism
}

\author{
Reza Javadrashid ${ }^{1}$, Mohammad Kazem Tarzamni ${ }^{1}$, Rosa Golshan Khalili ${ }^{1}$, Mohammad Reza Ghaffari ${ }^{2}$, \\ Khalil Ansarin ${ }^{2}$ and Daniel Fadaei Fouladi ${ }^{3,{ }^{*}}$ \\ ${ }^{1}$ Department of Radiology, Imam Reza Teaching Hospital, Tabriz University of Medical Sciences, Tabriz, Iran \\ ${ }^{2}$ Department of Lung and Respiratory Disease, Imam Reza Teaching Hospital, Tabriz University of Medical Sciences, Tabriz, Iran \\ ${ }^{3}$ Neurosciences Research Center, Tabriz University of Medical Sciences, Tabriz, Iran \\ "Corresponding author: Daniel Fadaei Fouladi, Neurosciences Research Center, Tabriz University of Medical Sciences, Golgasht St, Tabriz, Iran. Tel: +98-9144122542, E-mail: \\ fouladi.daniel@yahoo.com
}

Received 2017 August 04; Revised 2017 October 16; Accepted 2018 April 11.

\section{Abstract}

Background: Pulmonary embolism (PE) is a potentially lethal condition if left untreated. There have been many efforts to find prognostic factors in patients with PE. The descending aorta enhancement (DAE) to main pulmonary artery enhancement (MPAE) ratio is a rather new imaging finding that has been suggested for prognostic purposes in such patients.

Objectives: To examine the prognostic value of DAE/MPAE in massive/submassive PE.

Patients and Methods: A total of 47 patients with massive/submassive acute PE and compromised right ventricular function were studied prospectively. The Hounsfield units of DAE and MPAE were obtained on pulmonary computed tomography angiography (PCTA). The DAE/MPAE ratio was compared between two groups of patients with and without in-hospital major adverse event/30day mortality.

Results: Twenty-four patients (51.1\%) were hemodynamically unstable at the time of admission. Endotracheal intubation and cardiopulmonary resuscitation were indicated in $27.7 \%(n=13)$ and $10.6 \%(n=5)$ of patients, respectively. The rate of PE-unrelated adverse events or mortality was 10.6\%. High correlations were present between observers in terms of reported DAE and MPAE(intraclass correlation coefficient $=0.99$ for both). No significant association was found between DAE/MPAE and the occurrence of PE-related or unrelated in-hospital major adverse event or 30-day mortality. A significant reverse correlation was observed between DAE/MPAE and patients' age (Pearson $\mathrm{r}=-0.47, \mathrm{P}=0.001$ ).

Conclusion: DAE/MPAE measured on PCTA may not predict PE-related or PE-unrelated poor outcome in patients with massive or submassive pulmonary embolism.

Keywords: Multidetector Computed Tomography, Pulmonary Embolism, Prognosis, Enhancement

\section{Background}

Pulmonary embolism (PE) is a potentially fatal condition with a short-term mortality rate ranging from $1 \%$ in hemodynamically stable patients to over $90 \%$ in those with severely compromised cardiorespiratory function (1). In case of massive PE and a compromised right ventricle, the mortality rate may reach to over 50\% (2). Sub-massive PE could also be complicated with right ventricular dysfunction and the prognosis may be poor (3).

Pulmonary computed tomographic angiography (PCTA) is now the mainstay imaging technique for diagnosis and risk stratification in patients with PE $(4,5)$. Up to now many investigators have tried to suggest PCTA-based prognostic parameters in $\mathrm{PE}$, some of which originate from this assumption that the right side of the heart undergoes strain and dysfunction because of clot burden in such cases (6-8). Most of these presumably prognostic parameters, however, are controversial in terms of accuracy and reproducibility (9-12).

In one of these studies, Park et al. (13) suggested that descending aorta enhancement to main pulmonary artery enhancement (DAE/MPAE) could predict PE-related major adverse events in patients with massive pulmonary embolism. However, because of insufficient supporting studies and a potential effect of racial and regional differences on the incidence of PE-related mortality $(14,15)$, this conclusion needs to be verified in further investigations. 


\section{Objectives}

The objective of the present study is to test the prognostic value of DAE/MPAE in a group of white patients with massive/ sub-massive PE.

\section{Patients and Methods}

\subsection{Study Design and Patients}

In this prospective cohort study, a total of 47 Caucasian patients with acute massive or sub-massive PE were recruited from a teaching hospital between August 2013 and December 2014. Patients without PE-related right ventricular dysfunction, with a positive history of right ventricular dysfunction, with previous PE, and with at least 3 days delay between PCTA and transthoracic echocardiography were not included. The ethics committee of our university approved this study and informed written consents were obtained from participants.

\subsection{Right Ventricular Dysfunction}

Any of the following findings in transthoracic echocardiography indicated right ventricular dysfunction (16): right ventricular end-diastolic diameter/left ventricle enddiastolic diameter $\geq 0.9$, motion abnormality of the right ventricle wall, and tricuspid regurgitation jet $\geq 2.8 \mathrm{~m} / \mathrm{sec}$.

\subsection{Massive and Sub-Massive Categorization}

Patients hemodynamically stable were categorized as "with sub-massive PE" and patients with hemodynamic instability were categorized as "with massive PE". Hemodynamic instability was present when a patient admitted with systolic hypotension (systolic blood pressure $\leq 90$ $\mathrm{mmHg}$ ) and/or syncope (13).

\subsection{Outcome Measures}

Requirement for endotracheal intubation and/or cardiopulmonary resuscitation during hospitalization was considered as PE-related major adverse events. Any PEunrelated major adverse event was also documented at the same time (13). Short-term PE-related and PE-unrelated mortality was defined as expiration within 30 days postPCTA (12).

\subsection{Spiral PCTA Protocol and Variables}

Contrast - enhanced, non - electrocardiography - gated spiral PCTA was performed with a 64-slice multidetector machine (SOMATOM Sensation 64, Siemens, Germany) following standard protocols (17): collimation, $1 \mathrm{~mm}$; pitch, 0.8 ; reconstruction increment, $1 \mathrm{~mm}$; rotation time, 0.33 second; $120 \mathrm{kV}$ per slice; 120 - $140 \mathrm{mAs}$.

Imaging was carried out after intravenous administration of $50 \mathrm{~mL}$ of iopromide (Ultravist 370, Schering AG,
Berlin, Germany) at a rate of $4 \mathrm{~mL} / \mathrm{sec}$, which was followed by infusion of $50 \mathrm{~mL}$ saline solution at the same rate. Test bolus technique was used to define scan-delay. On this basis, scanning began 5 seconds after the pulmonary artery reached 100 Hounsfield unit (HU), as described by the original study (13). CT imaging was carried out from the lowest hemidiaphragm to the top of the lungs (18).

Two attending radiologists with over 10 years of experience reviewed CT images on independent workstations. In the first place, they verified the diagnosis of PE as partial or complete occlusion of the pulmonary arteries by an endoluminal central filling defect (18). Location of the largest pulmonary artery was examined from the identified pulmonary embolism and recorded as the main pulmonary artery, lobar pulmonary artery, segmented pulmonary artery and sub-segmented pulmonary artery (13).

To measure the mean attenuation in vessels on transaxial CT images, a circular region of interest (ROI) was placed on the descending aorta at the level of pulmonary bifurcation and on the main pulmonary artery (Figure 1) (13). The pulmonary artery obstruction score (PAOS) was determined according to the method suggested by Qanadli et al. (19) for assessment of clot burden.

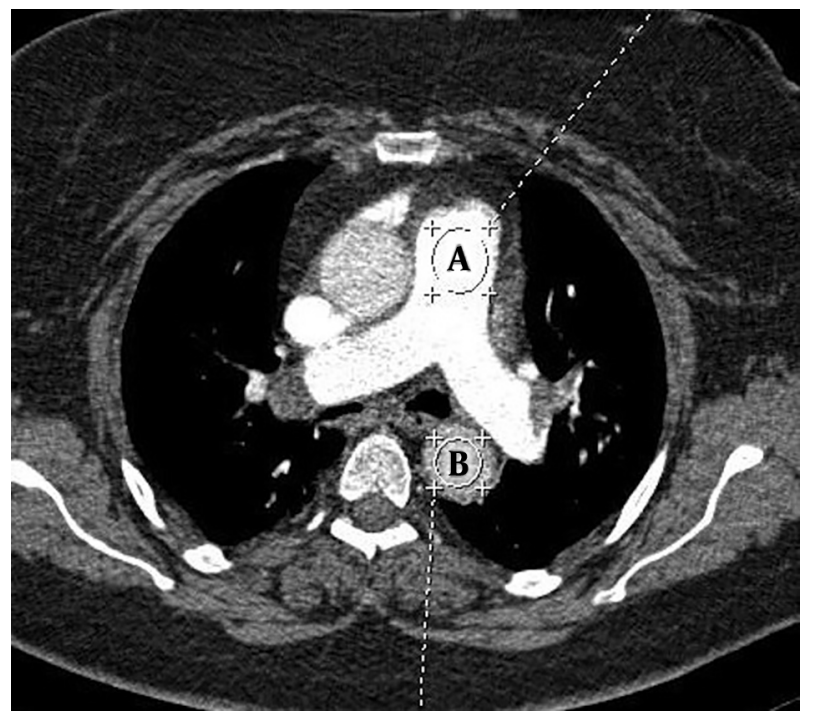

Figure 1. Transverse spiral computed tomographic angiographic image (50 mL of contrast material, $6 \mathrm{~mL} / \mathrm{sec}$ flow rate) of the pulmonary arteries at the level of the pulmonary bifurcation. Region of interests are shown on the main pulmonary artery (A) and on the descending aorta (B)

\subsection{Statistical Analysis}

SPSS software version 19.0 (IBM Corp. Released 2010. IBM SPSS Statistics for Windows, Version 19.0. Armonk, $\mathrm{NY}$ ) was used for statistical analysis. Independent samples t test, Mann-Whitney $U$ test and Kruskal Wallis test were 
used where appropriate. Pearson coefficient (r) was calculated to examine correlations between study variables. The intraclass correlation coefficient was used to assess interobserver variability. The significance level was set at $\mathrm{P} \leq$ 0.05 .

\section{Results}

Patients' demographic data are summarized in Table 1. The mean reported DAE by the first observer was 135.34 \pm 61.14 (range, 62.40 -376.00) and the mean reported DAE by the second observer was $136.01 \pm 96.31$ (range, 61.00 - 379.00). The intra-class correlation coefficient was very high (0.99) for the two readings. The mean DAE by the two observers was $135.68 \pm 61.12$. The mean reported MPAE by the first observer was $397.29 \pm 96.31$ (range, 156.00 690.00) and the mean reported MPAE by the second observer was $397.16 \pm 95.69$ (range, 156.00 - 686.00). Again, a very high intra-class correlation coefficient (0.99) was present between the two readings. The mean MPAE by the two observers was $397.16 \pm 95.69$. The mean DAE/MPAE was calculated at $0.36 \pm 0.19$ (range, 0.13 - 0.99).

In hospital endotracheal intubation and cardiopulmonary resuscitation (CPR) were performed in 13 (27.7\%) and five (10.6\%) patients, respectively. The 30-day PE-related mortality rate was $25.5 \%(n=12)$, with no PE-unrelated death occurred during the same period of time. PEunrelated major adverse events occurred in five patients (10.6\%), including sepsis $(n=2)$, intraventricular hemorrhage $(n=1)$, gastrointestinal hemorrhage $(n=1)$ and acute renal failure $(n=1)$.

A significant, reverse correlation was present between DAE/MPAE and patients' age (Pearson $\mathrm{r}=-0.47, \mathrm{P}<0.001$ ) (Figure 2). No significant correlation was observed between DAE/MPAE and PAOS (Pearson $\mathrm{r}=-0.03, \mathrm{P}=0.86$ ), and between DAE/MPAE and hospital stay (Pearson $r=0.16, \mathrm{P}=$ $0.33)$. DAE/MPAE values stratified by study variables are set out in Table 2. No significant association was found in this regard.

The median PAOS was significantly higher in patients with PE-related in-hospital major adverse event/30-day mortality compared to patients without PE-related inhospital major adverse event/30-day mortality (5.00 with interquartile range [IQR], 6.00 vs. 12.00 with IQR, 8.00; P = $0.03)$.

The rate of massive PE was significantly higher in patients who underwent intubation compared to those who did not (92.3\% vs. 35.3\%; $\mathrm{P}<0.001$ ), in patients who underwent CPR compared to patients who did not (100\% vs. $45.2 \% ; \mathrm{P}=0.05$ ), in patients who expired within 30 days after PCTA compared to patients who did not (100\% vs. $45.2 \%$; $\mathrm{P}=0.05)$, and in patients with bad outcome in general compared to those without (92.3\% vs. 35.3\%; $\mathrm{P}<0.001$ ).

\begin{tabular}{|c|c|}
\hline Variable & Datum \\
\hline \multicolumn{2}{|l|}{ Sex } \\
\hline Male & $21(44.7)$ \\
\hline Female & $26(55.3)$ \\
\hline Age, y & $61.72 \pm 14.53(29-83)$ \\
\hline \multicolumn{2}{|l|}{ Presenting complaint } \\
\hline Dyspnea & $16(34)$ \\
\hline Dyspnea and hypotension & $16(34)$ \\
\hline Dyspnea and chest pain/discomfort & $4(4.5)$ \\
\hline Hypotension & $4(8.5)$ \\
\hline Dyspnea and mental change & $2(4.3)$ \\
\hline Dyspnea and hypotension & $2(4.3)$ \\
\hline Chest pain/discomfort & $1(2.1)$ \\
\hline Syncope & $1(2.1)$ \\
\hline Hypotension and chest pain/discomfort & $1(2.1)$ \\
\hline \multicolumn{2}{|l|}{ PE extent } \\
\hline Massive & $24(51.1)$ \\
\hline Sub-massive & $23(48.9)$ \\
\hline \multicolumn{2}{|l|}{ PE location } \\
\hline Main & $31(66)$ \\
\hline Lobar & $13(27.7)$ \\
\hline Segmental & $3(6.4)$ \\
\hline PAOS (Based on Qanadli method), \% & $11.81 \pm 2.15(5-19)$ \\
\hline Thrombolysis & $45(95.7)$ \\
\hline Embolectomy & $5(10.6)$ \\
\hline Hospital stay, day & $11.63 \pm 6.11(1-30)$ \\
\hline
\end{tabular}

The median DAE/MPAE was 0.28 (IQR, 0.17) in patients with massive PE and unfavorable outcome ( $\mathrm{n}=12$ ), 0.32 (0.39) in patients with massive PE and favorable outcome $(\mathrm{n}=12)$ and $0.31(0.21)$ in patients with sub-massive PE and favorable outcome $(n=22)$. The three groups were comparable in this regard $(\mathrm{P}=0.63)$ (Figure 3 ).

\section{Discussion}

In the present work, the two groups of patients with and without PE-related adverse events/ mortality were comparable in terms of the median DAE/MPAE. For the first time in 2012, Park et al. (13) suggested that DAE/MPAE might predict PE-related major adverse events in patients with massive pulmonary embolism. The authors assumed that 
Table 2. Descending Aorta Enhancement to Main Pulmonary Artery Enhancement (DAE/MPAE) in Patients with Massive or Sub-Massive Pulmonary Embolism (PE) According to Study Variables ${ }^{\mathrm{a}, \mathrm{b}, \mathrm{c}}$

\begin{tabular}{|c|c|c|c|}
\hline Variable & No. of patients & DAE/MPAE & Pvalue \\
\hline Sex & & & $0.27^{*}$ \\
\hline Male & 21 & $0.33 \pm 0.19$ & \\
\hline Female & 26 & $0.39 \pm 0.19$ & \\
\hline PE extent & & & $0.77^{*}$ \\
\hline Massive & 24 & $0.35 \pm 0.19$ & \\
\hline Submassive & 23 & $0.37 \pm 0.19$ & \\
\hline PE location & & & $0.41^{*}$ \\
\hline $\begin{array}{l}\text { Main pulmonary } \\
\text { artery }\end{array}$ & 31 & $0.35 \pm 0.16$ & \\
\hline Other & 16 & $0.39 \pm 0.24$ & \\
\hline Endotracheal intubation & & & 0.31 \\
\hline Negative & 34 & $0.31(0.23)$ & \\
\hline Positive & 13 & $0.26(0.17)$ & \\
\hline $\begin{array}{l}\text { Cardiopulmonary } \\
\text { resuscitation }\end{array}$ & & & 0.89 \\
\hline Negative & 42 & $0.30(0.21)$ & \\
\hline Positive & 5 & $0.38(0.21)$ & \\
\hline Mortality (30-day) & & & 0.63 \\
\hline No & 42 & $0.31(0.18)$ & \\
\hline Yes & 5 & $0.24(0.34)$ & \\
\hline $\begin{array}{l}\text { PE-unrelated major adverse } \\
\text { events }\end{array}$ & & & 0.47 \\
\hline Negative & 42 & $0.31(0.20)$ & \\
\hline Positive & 5 & $0.25(0.30)$ & \\
\hline $\begin{array}{l}\text { PE-related major adverse } \\
\text { events/mortality }\end{array}$ & & & 0.47 \\
\hline Negative & 32 & $0.31(0.22)$ & \\
\hline Positive & 15 & $0.26(0.26)$ & \\
\hline
\end{tabular}

${ }^{\mathrm{a}}$ Data are presented as mean $\pm \mathrm{SD}$ or median (interquartile range).

${ }^{\mathrm{b}}$ Independent samples t test $\left({ }^{*}\right)$ or Mann-Whitney U test are used for comparisons.

${ }^{\mathrm{C}} \mathrm{P}$ value $<0.05$ is statistically significant.

in case of severe PE and right ventricular dysfunction more contrast agents are retained in the pulmonary circulation, leading to decreased DAE and increased MPAE.

Most likely this assumption dates back to 1998, when Miller et al. (20) suggested that the reflux of contrast dye into the inferior vena cava might be a sign of right-sided heart dysfunction. Later on, Kang et al. (21) confirmed their findings, but Collomb et al. (22) found no prognostic role for the reflux of contrast dye into the inferior vena cava in PE patients. In line with our finding, a recent study by Hefeda and Elmasry (23) on 32 patients with PE also documented no significant difference between survivors

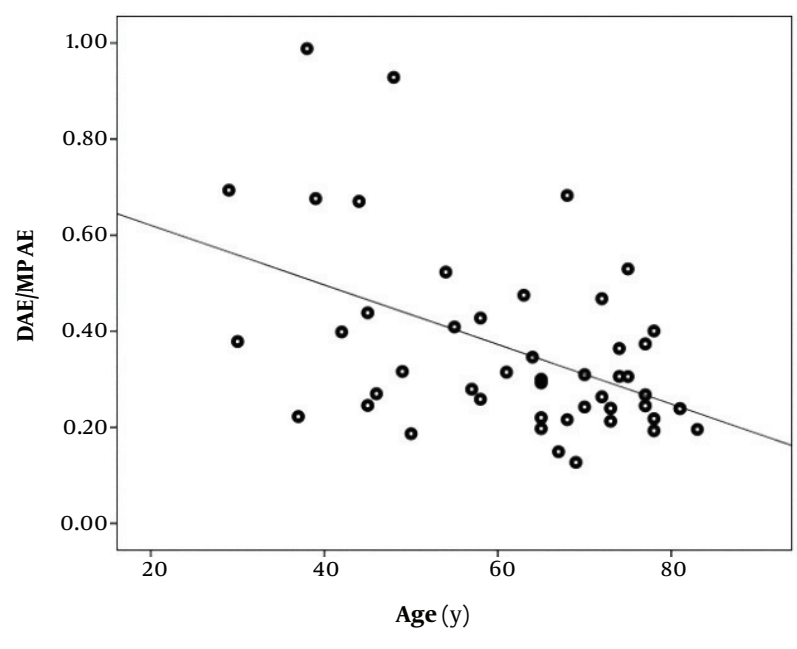

Figure 2. Simple scatter plot of descending aorta enhancement to main pulmonary artery enhancement (DAE/MPAE) ratio against age of patients with massive or submassive pulmonary embolism (Pearson $\mathrm{r}=-0.47, \mathrm{P}<0.001$ )

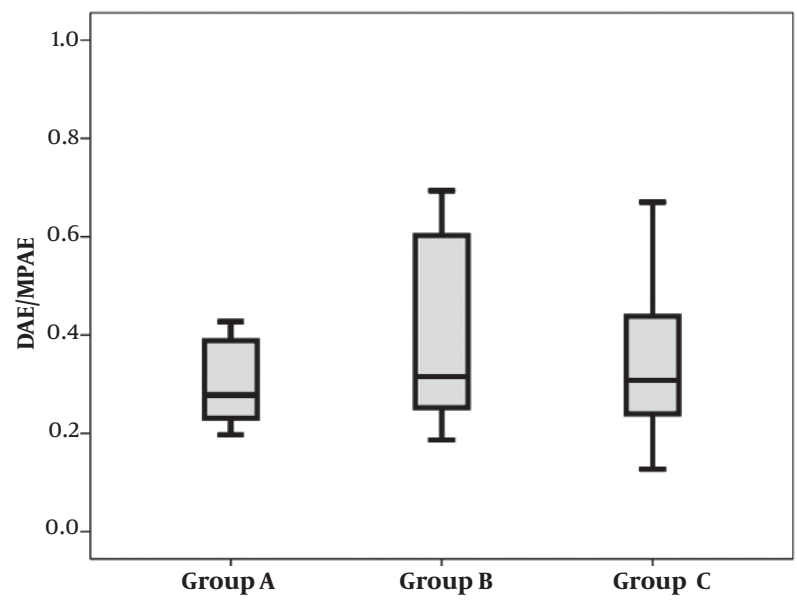

Figure 3. Box plots of descending aorta enhancement to main pulmonary artery enhancement (DAE/MPAE) ratio in patients with massive pulmonary edema (PE) and unfavorable outcome (group A), in patients with massive PE and favorable outcome (group B) and in patients with sub-massive PE and favorable outcome (group C).

$(\mathrm{n}=23)$ and non-survivors $(\mathrm{n}=9)$ in terms of the mean DAE/MPAE.

Many factors may affect contrast enhancement including the amount of injected contrast material, flow rate, and in particular, the scan delay (24-26). It should be noted that empiric bolus timing could be difficult especially when the pressure of pulmonary artery is elevated and poor performance of the right cardiac side is present (26). In addition to these parameters, the presence of bronchopulmonary collateral vessels in some patients with previous chronic inflammatory diseases may serve as an extensive left-to-right shunt, and affects the attenuation of 
the pulmonary vessels $(25,27)$. A preexisting patent foramen ovale may also cause insufficient attenuation of the pulmonary arteries. Although this condition may seem rare, in a previous study patent foramen ovale caused abnormal contrast dynamics in $16 \%$ of patients with suspected $P E(26)$. Other miscellaneous factors that may cause inadequate pulmonary artery enhancement in PE patients are air space consolidations, intracardiac shunts, preexisting undiagnosed heart failure, high cardiac output, and obstruction of the superior vena cava $(24-26,28)$.

Besides contrast material administration, respiration may also dramatically influence scan quality in PE patients, because the dedicated guideline of breathing during computed tomographic scanning is usually hard to follow by patients with suspected massive or submassive PE $(24,25$, 29).

It has been suggested that DAE/MPAE could be obtained more objectively and more reliably than similar previously defined prognostic factors in association with right ventricular dysfunction (13). We also showed very low inter-observer variation in reporting DAE/MPAE in the present work. On the basis of discussed parameters in association with attenuation of the pulmonary vasculature, however, a considerable variation could be expected with employment of DAE/MPAE as a prognostic factor, as the present study confirmed.

It has been proposed that a mechanical obstruction by the intravascular clot is not the sole contributor to pulmonary vascular resistance and other factors such as systemic arterial hypoxemia, reflex vasoconstriction and release of vasoactive agents may also come to play (30). In addition, many clots lodge in small peripheral pulmonary arteries with no significant contribution to overall obstruction in pulmonary vasculature in PE (31). Therefore, the degree of enhancement of pulmonary vasculature in PE may not reflect actual severity of the obstruction. An insignificant correlation between DAE/MPAE and PAOS in the present work supports this surmise.

Finally, we found a significant reverse correlation between patients' age and DAE/MPAE. Age is a known risk factor for untoward consequences in patients with PE (32). In a recent study, our group found age as the only prognostic factor in patients with PE, which was independent of right heart failure and PAOS (33). In the international cooperative pulmonary embolism registry, age of $>70$ years has been suggested as a negative prognostic factor in patients with PE (34). At the same time, it has been shown that an increasing age aggravates right ventricle (RV) dysfunction (35). Accordingly, it could be suggested that a significant association between DAE/MPAE and patients' outcome in PE is only the effect of age. Unfortunately Park et al. did not examine age as a prognostic factor in their study. The mean age of their patients (71.4 years), however, was significantly more than that in the present work (61.7 years) and in Hefeda's series (56.8 years).

Our sample size is larger than that of the original report (13), but for more definite prognostic purposes, larger sample sizes should be studied in future works. In addition, although a 3-month follow-up encompasses the critical period in patients with PE (3), longer follow-ups are needed to fully examine the prognostic importance of DAE/MPAE.

As mentioned earlier, some pathologies such as air space consolidations, intracardiac shunts, preexisting undiagnosed heart failure, high cardiac output, and obstruction of the superior vena cava may affect the prognostic value of DAE/MPAE in PE. Although many of these conditions are rare, more controlled studies are needed to reach a definite conclusion in this regard.

Finally, accurate separation of PE-related and unrelated complications/death is impossible and this may limit drawing a solid conclusion in examining the prognostic value of DAE/MPAE in PE. It should be noted, however, that in the present study we showed significant associations between the extent (and severity) of PE and PE-related complications/mortality, which may, at least partly, confirm the accuracy of proposing those outcome variables as PErelated ones.

In summary, this study showed that DAE/MPAE on PCTA could not be considered as a reliable short-term prognostic factor in patients with massive or sub-massive PE.

\section{Footnotes}

Authors' Contributions: None declared.

Financial Disclosure: None declared.

Funding/Support: None declared.

\section{References}

1. Kurkciyan I, Meron G, Sterz F, Janata K, Domanovits H, Holzer M, et al. Pulmonary embolism as a cause of cardiac arrest: presentation and outcome. Arch Intern Med.2000;160(10):1529-35. doi:10.1001/archinte.160.10.1529. [PubMed: 10826469].

2. Kucher N, Rossi E, De Rosa M, Goldhaber SZ. Massive pulmonary embolism. Circulation. 2006;113(4):577-82. doi: 10.1161/CIRCULATIONAHA.105.592592. [PubMed: 16432055].

3. Sanchez O, Trinquart L, Colombet I, Durieux P, Huisman MV, Chatellier G, et al. Prognostic value of right ventricular dysfunction in patients with haemodynamically stable pulmonary embolism: a systematic review. Eur Heart J. 2008;29(12):1569-77. doi: 10.1093/eurheartj/ehn208. [PubMed: 18495689].

4. Torbicki A, Perrier A, Konstantinides S, Agnelli G, Galie N, Pruszczyk $\mathrm{P}$, et al. Guidelines on the diagnosis and management of acute pulmonary embolism: the Task Force for the Diagnosis and Management of Acute Pulmonary Embolism of the European Society of Cardiology (ESC). Eur Heart J. 2008;29(18):2276-315. doi: 10.1093/eurheartj/ehn310. [PubMed: 18757870].

5. Schoepf UJ, Costello P. CT angiography for diagnosis of pulmonary embolism: state of the art. Radiology. 2004;230(2):329-37. doi: 10.1148/radiol.2302021489. [PubMed: 14752178]. 
6. ten Wolde M, Sohne M, Quak E, Mac Gillavry MR, Buller HR. Prognostic value of echocardiographically assessed right ventricular dysfunction in patients with pulmonary embolism. Arch Intern Med. 2004;164(15):1685-9. doi: 10.1001/archinte.164.15.1685. [PubMed: 15302640].

7. van der Meer RW, Pattynama PM, van Strijen MJ, van den BergHuijsmans AA, Hartmann IJ, Putter $\mathrm{H}$, et al. Right ventricular dysfunction and pulmonary obstruction index at helical CT: prediction of clinical outcome during 3-month follow-up in patients with acute pulmonary embolism. Radiology. 2005;235(3):798-803. doi: 10.1148/radiol.2353040593. [PubMed: 15845793].

8. Coutance G, Cauderlier E, Ehtisham J, Hamon M, Hamon M. The prognostic value of markers of right ventricular dysfunction in pulmonary embolism: a meta-analysis. Crit Care. 2011;15(2):R103. doi: 10.1186/cc10119. [PubMed: 21443777]. [PubMed Central: PMC3219376].

9. Goldhaber SZ. Echocardiography in the management of pulmonary embolism. Ann Intern Med. 2002;136(9):691-700. doi: 10.7326/00034819-136-9-200205070-00012. [PubMed: 11992305].

10. Araoz PA, Gotway MB, Trowbridge RL, Bailey RA, Auerbach AD, Reddy GP, et al. Helical CT pulmonary angiography predictors of in-hospital morbidity and mortality in patients with acute pulmonary embolism. J Thorac Imaging. 2003;18(4):207-16. doi: 10.1097/00005382200310000-00001. [PubMed: 14561905].

11. Stein PD, Beemath A, Matta F, Goodman LR, Weg JG, Hales CA, et al. Enlarged right ventricle without shock in acute pulmonary embolism: prognosis. Am J Med. 2008;121(1):34-42. doi: 10.1016/j.amjmed.2007.06.032. [PubMed: 18187071]. [PubMed Central: PMC2219923].

12. Araoz PA, Gotway MB, Harrington JR, Harmsen WS, Mandrekar JN. Pulmonary embolism: prognostic CT findings. Radiology. 2007;242(3):889-97. doi: 10.1148/radiol.2423051441. [PubMed: 17325073].

13. Park CY, Yoo SM, Rho JY, Ji YG, Lee HY. The Ratio of Descending Aortic Enhancement to Main Pulmonary Artery Enhancement Measured on Pulmonary CT Angiography as a Finding to Predict Poor Outcome in Patients with Massive or Submassive Pulmonary Embolism. Tuberc Respir Dis (Seoul). 2012;72(4):352-9. doi: 10.4046/trd.2012.72.4.352. [PubMed: 23227076]. [PubMed Central: PMC3510286].

14. Ibrahim SA, Stone RA, Obrosky DS, Sartorius J, Fine MJ, Aujesky D. Racial differences in 30-day mortality for pulmonary embolism. Am J Public Health. 2006;96(12):2161-4. doi: 10.2105/AJPH.2005.078618. [PubMed: 17077409]. [PubMed Central: PMC1698166].

15. Zakai NA, McClure LA, Judd SE, Safford MM, Folsom AR, Lutsey PL, et al. Racial and regional differences in venous thromboembolism in the United States in 3 cohorts. Circulation. 2014;129(14):1502-9. doi: 10.1161/CIRCULATIONAHA.113.006472. [PubMed: 24508826]. [PubMed Central: PMC4098668].

16. Piazza G, Goldhaber SZ. Management of submassive pulmonary embolism. Circulation. 2010;122(11):1124-9. doi: 10.1161/CIRCULATIONAHA.110.961136. [PubMed: 20837937]. [PubMed Central: PMC2941210].

17. Ghuysen A, Ghaye B, Willems V, Lambermont B, Gerard P, Dondelinger $\mathrm{RF}$, et al. Computed tomographic pulmonary angiography and prognostic significance in patients with acute pulmonary embolism. Thorax. 2005;60(11):956-61. doi: 10.1136/thx.2005.040873. [PubMed: 16131526]. [PubMed Central: PMC1747227].

18. Furlan A, Aghayev A, Chang CC, Patil A, Jeon KN, Park B, et al. Shortterm mortality in acute pulmonary embolism: clot burden and signs of right heart dysfunction at CT pulmonary angiography. Radiology. 2012;265(1):283-93. doi: 10.1148/radiol.12110802. [PubMed: 22993221]. [PubMed Central: PMC3447174].

19. Qanadli SD, El Hajjam M, Vieillard-Baron A, Joseph T, Mesurolle B, Oliva VL, et al. New CT index to quantify arterial obstruction in pulmonary embolism: comparison with angiographic index and echocardiography. AJR Am J Roentgenol. 2001;176(6):1415-20. doi: 10.2214/ajr.176.6.1761415. [PubMed: 11373204].

20. Miller RL, Das S, Anandarangam T, Leibowitz DW, Alderson PO,
Thomashow B, et al. Association between right ventricular function and perfusion abnormalities in hemodynamically stable patients with acute pulmonary embolism. Chest.1998;113(3):665-70. doi: 10.1378/chest.113.3.665. [PubMed: 9515840].

21. Kang DK, Thilo C, Schoepf UJ, Barraza JM Jr, Nance JW Jr, Bastarrika $\mathrm{G}$, et al. CT signs of right ventricular dysfunction: prognostic role in acute pulmonary embolism. JACC Cardiovasc Imaging. 2011;4(8):841-9. doi: 10.1016/j.jcmg.2011.04.013. [PubMed: 21835376].

22. Collomb D, Paramelle PJ, Calaque O, Bosson JL, Vanzetto G, Barnoud D, et al. Severity assessment of acute pulmonary embolism: evaluation using helical CT. Eur Radiol. 2003;13(7):1508-14. doi: 10.1007/s00330002-1804-5. [PubMed: 12835961].

23. Hefeda MM, Elmasry MM. Prediction of short term outcome of pulmonary embolism: Parameters at 16 multi-detector CT pulmonary angiography. Egypt J Radiol Nucl Med. 2014;45(4):1089-98. doi: 10.1016/j.ejrnm.2014.05.011

24. Remy-Jardin M, Remy J. Spiral CT angiography of the pulmonary circulation. Radiology. 1999;212(3):615-36. doi: 10.1148/radiology.212.3.r99se02615. [PubMed:10478224].

25. Remy-Jardin M, Remy J, Artaud D, Fribourg M, Beregi JP. Spiral CT of pulmonary embolism: diagnostic approach, interpretive pitfalls and current indications. Eur Radiol. 1998;8(8):1376-90. doi 10.1007/s003300050557. [PubMed: 9853219].

26. Henk CB, Grampp S, Linnau KF, Thurnher MM, Czerny C, Herold CJ, et al. Suspected pulmonary embolism: enhancement of pulmonary arteries at deep-inspiration CT angiography-influence of patent foramen ovale and atrial-septal defect. Radiology. 2003;226(3):749-55. doi: 10.1148/radiol.2263012200. [PubMed:12601200].

27. Bookstein JJ, Silver TM. The angiographic differential diagnosis of acute pulmonary embolism. Radiology. 1974;110(1):25-33. doi: 10.1148/110.1.25. [PubMed: 4808537].

28. Gotway MB, Patel RA, Webb WR. Helical CT for the evaluation of suspected acute pulmonary embolism: diagnostic pitfalls. J Comput Assist Tomogr. 2000;24(2):267-73. doi: 10.1097/00004728-20000300000016. [PubMed: 10752891].

29. Kauczor HU, Heussel CP, Thelen M. Update on diagnostic strategies of pulmonary embolism. Eur Radiol. 1999;9(2):262-75. doi 10.1007/s003300050666. [PubMed: 10101649].

30. Wood KE. Major pulmonary embolism: review of a pathophysiologic approach to the golden hour of hemodynamically sig nificant pulmonary embolism. Chest. 2002;121(3):877-905. doi: 10.1378/chest.121.3.877. [PubMed: 11888976].

31. Ghaye B, Ghuysen A, Bruyere PJ, D'Orio V, Dondelinger RF. Can CT pulmonary angiography allow assessment of severity and prognosis in patients presenting with pulmonary embolism? What the radiologist needs to know. Radiographics. 2006;26(1):23-39. discussion 39-40. doi: 10.1148/rg.261055062. [PubMed:16418240].

32. Aujesky D, Roy PM, Le Manach CP, Verschuren F, Meyer G, Obrosky DS, et al. Validation of a model to predict adverse outcomes in patients with pulmonary embolism. Eur Heart J. 2006;27(4):476-81. doi: 10.1093/eurheartj/ehi588. [PubMed:16207738].

33. Javadrashid R, Mozayan M, Tarzamni MK, Ghaffari MR, Fouladi DF. Spiral computed tomographic pulmonary angiography in patients with acute pulmonary emboli and no pre-existing comorbidity: a prospective prognostic panel study. Eur Radiol. 2015;25(1):147-54. doi: 10.1007/s00330-014-3383-7. [PubMed: 25163897].

34. Goldhaber SZ, Visani L, De Rosa M. Acute pulmonary embolism: clinical outcomes in the International Cooperative Pulmonary Embolism Registry (ICOPER). Lancet. 1999;353(9162):1386-9. doi: 10.1016/S01406736(98)07534-5. [PubMed:10227218].

35. Kukulski T, Hubbert L, Arnold M, Wranne B, Hatle L, Sutherland GR. Normal regional right ventricular function and its change with age: a Doppler myocardial imaging study. J Am Soc Echocar diogr. 2000;13(3):194-204. doi: 10.1067/mje.2000.103106. [PubMed: 10708468] 